J. ENVIRON. QUAL., VOL. 32, NOVEMBER-DECEMBER 2003

ROBLES ET AL.: PINE NEEDLES AS BIOINDICATORS OF AIR POLLUTION

\title{
Phenols and flavonoids in Aleppo Pine Needles as Bioindicators of Air Pollution
}

\author{
Christine Robles, Stéphane Greff, Vanina Pasqualini, Suzanne Garzino, Anne Bousquet-Mélou, \\ Catherine Fernandez* Nathalie Korboulewsky, and Gilles Bonin
}

\begin{abstract}
The aim of the present study is to assess whether certain ecophysiological responses (contents of total phenols, total proanthocyanidins, and total and simple flavonols), in the needles of Aleppo pines (Pinus halepensis Mill.) may be valid bioindicators for the assessment of the air quality. Samples were taken at five natural sites polluted by various pollutants $\left(\mathrm{NO}, \mathrm{NO}_{2}\right.$, other $\mathrm{NOx}, \mathrm{SO}_{2}$, and $\mathrm{O}_{3}$ ). The results show a decrease in total phenol concentrations with levels of nitrogen oxide pollutions (significant negative correlations between the total phenol concentrations and concentrations of $\mathrm{NO}, \mathrm{NO}_{2}$, and other $\mathrm{NO}_{\mathrm{x}}$ ). Total flavonoids (total flavonols and proanthocyanidins) are useful bioindicators for ozone pollution (significant negative correlations between total proanthocyanidins and the concentrations of ozone and significant positive correlations between total flavonols and the ozone pollution). Sulfur dioxide pollution is distinguished by low concentrations in quercetin, isorhamnetin, and kaempferol (significant negative correlations between these simple flavonols and the concentrations of $\mathrm{SO}_{2}$ ). This work confirms the strong interest of using the phenolic compounds of Pinus halepensis as biological indicators of air quality.

C. Robles, S. Greff, S. Garzino, A. Bousquet-Mélou, C. Fernandez, N. Korboulewsky, and G. Bonin, Institut Méditerranéen d'Ecologie et Paléoécologie (IMEP)-UMR CNRS 6116, Laboratoire de Biosystématique et d'Ecologie Méditerranéenne (LBEM), Université de Provence, FST St. Jérome, Case 421 bis, Avenue Escadrille Normandie Niemen, 13397 Marseille, Cedex 20, France; V. Pasqualini, Université de Corse, Faculté des Sciences et Techniques, Equipe Ecosystèmes littoraux, B.P. 52, 20250 Corte, France. Sponsoring organizations: Conseil Régional Provence Alpes-Côtes d'Azur, AIRFOBEP and AIRMARAIX. Received 31 Jan. 2003. *Corresponding author (catherine.fernandez@up.univ-mrs.fr).
\end{abstract}

Abbreviations: $\mathrm{NO}_{\mathrm{x}}$, nitrogen oxides other than $\mathrm{NO}$ and $\mathrm{NO}_{2}$; PCA, principle component analyses; $\mathrm{UV}$, ultraviolet rays.

The quality of the air is now monitored daily in sensitive areas by numerous organizations specializing in air quality control (Bortnick and Stetzer, 2002). However, the impact of the various atmospheric pollutants on living organisms remains a poorly known phenomenon. Observation of the reactions of a living organism exposed to air pollution under natural conditions is necessary and some compounds formed in these reactions may be used as bioindicators. Bioindication is defined as the demonstration of the impact of environmental factors on animal or plant organisms. The response of the organisms reflects the complex effects of harmful substances, not only by showing the synergic effects of these substances, but also by integrating the time factor (Rossbach et al., 1999).

The bioindication of air quality has been described in numerous studies on plants (Zobel and Nighswander, 1991; Rautio et al., 1998; Rossbach et al., 1999; Rahman et al., 2000; Vassileva et al., 2000; Conti and Cecchetti, 2001; Godefroid, 2001). A wide range of diagnostic methods is used and may be applied at variable levels of observation: absence or presence of species (Giordani et al., 2002), morphological variations, presence of necroses or growth and 
development disturbances (Impens and Delcarte, 1995; Manning et al., 2002), or the occurrence of internal physiological alterations (Rossbach et al., 1999). In the latter case, analysis involves the measurement of certain chemical compounds contained in the plants as revealing a particular environmental state. In particular, the impact of air pollutants is often studied on the basis of experimentation under controlled conditions, each pollutant being generally tested in isolation (Peñuelas et al., 1996; Rodrigues et al., 1996). Studies performed under natural conditions are rare and sometimes only deal with the impact of a single type of pollutant (Karlsson et al., 1995; Oleksyn et al., 1999; Chappelka et al., 1999). However, the validation of a bioindicator requires the undertaking of experiments under natural conditions.

Among the chemical compounds in plants, secondary metabolites are of great importance in plant-environment relationships in particular the phenolic compounds (e.g., phenols and flavonoids; Haslam, 1989; Rhodes, 1994). These phenolic compounds are of particular interest because of their involvement in the response of the plant to environmental stress, such as a deficit in nutrients, the impact of ultraviolet rays (UV) or air pollution (Vogt et al., 1991; Chaves et al., 1993; Muzika, 1993; Peñuelas et al., 1996; Cooper-Driver and Bhattacharya, 1998; Pisani and Distel, 1998). The phenolic compounds include a wide range of substances possessing one or several hydroxyls, bound to at least one aromatic ring (Waterman and Mole, 1994). While numerous studies have investigated the impact of air pollutants on concentrations of total phenols (Karolewski, 1990; Giertych and Karolewski, 1993; Karolewski and Giertych, 1994; Karolewski and Giertych, 1995; Peñuelas et al., 1996; Giertych et al., 1999), no research has been done on flavonols and flavonoids except a recent study on the impact of heavy metal air pollution on Betula (Loponen et al., 2001).

To determine whether phenolic compounds may be used as air quality bioindicators, experiments should be performed in the natural environment. The region of Marseille (France) was chosen as experimental base because of the high level of human pressure in the area. The aim of this study was to analyze concentrations of total phenols and flavonoids (total proanthocyanidins, total and simple flavonols) in the needles of ???Aleppo pines (Pinus halepensis Mill.), at various sites exposed to pollution by $\mathrm{O}_{3}, \mathrm{SO}_{2}$, and $\mathrm{NO}$, to determine whether these compounds may be used as bioindicators of air quality. Pinus halepensis was chosen for the study because it is a widespread Mediterranean tree and can be found in both natural and urban environments.

\section{MATERIAL AND METHODS}

\section{Study Sites and Plant Material}

Five study sites, situated in the vicinity of Marseille (South of France), were chosen for the experiments (1. Cadarache, 2. Gardanne, 3. St. Marguerite, 4. Sausset-les-Pins, 5. Martigues, Fig. 1). The sites are located in a geographically limited area with the same bioclimatic and edaphic conditions to minimize variations in these environmental factors. These sites were chosen according to their air pollutant levels measured by AIRFOBEP and AIRMARAIX (the organizations that are responsible for monitoring the air quality in the region). Since industrial activity and road transport represent the major sources of air pollution in this area, five types of pollutants were considered for this study: $\mathrm{NO}, \mathrm{NO}_{2}, \mathrm{NO}_{\mathrm{X}}$ (excluding $\mathrm{NO}$ and $\mathrm{NO}_{2}$ ), $\mathrm{SO}_{2}$, and $\mathrm{O}_{3}$. Each air pollutant was measured by automatic specific analyzer of each pollutant (AIRFOBEP, 
2000). Each atmospheric pollutant was measured every $15 \mathrm{~min}$. at each study station over the period between 7 Dec. 2000 and 7 Feb. 2001 (R. Thieleke personal communication, ?date : Table 1).

Sampling was performed on 7 Feb. 2001 with the objective to obtain current needles that are $1-y r$ old and because this period corresponds to the winter dry season. For each site, the first year needles from six specimens were randomly collected at all level of the canopy. For each tree, all the current needles collected at all level of the canopy were pooled to obtain one sample per tree. To avoid age-related variations, the samples were taken on specimens of about $30 \mathrm{yr}$. The age of each specimen was previously determined on cores by means of a Pressler drill???. The needles were oven dried at $40^{\circ} \mathrm{C}$ for $1 \mathrm{wk}$, then ground and stored in darkness at room temperature.

\section{Chemical Processing}

The method of extraction of the phenols is based on the work of Peñuelas et al. (1996). Onehalf gram (dry weight) of needles per sample was extracted with $20 \mathrm{~mL}$ of a $70 \%$ aqueous methanol solution (v/v) acidified by a few drops of $1 \mathrm{M} \mathrm{HCl}$. The mixture is left at ambient temperature for $1.5 \mathrm{~h}$, and then filtered. Quantification of the total phenols is done by colorimetric reaction using Folin-Ciocalteu reagent, following the method of Marigo (1973). After $1 \mathrm{~h}$, the reaction is completed and measured at $720 \mathrm{~nm}$ on a Phillips PU 8620 spectrophotometer?(manufacturer and location). The quantitative results are expressed with reference to gallic acid as Peñuelas et al. (1996).

For the extraction and the quantification of the flavonoids (total proanthocyanidins, total and simple flavonols), we have used the method described on Pinus halepensis needles by Kaundun et al. (1998). Two grams (dry weight) of needles are put into suspension in $100 \mathrm{~mL}$ of $2 \mathrm{M} \mathrm{HCl}$. The solution is heated to $80^{\circ} \mathrm{C}$ in a water bath with reflux for $50 \mathrm{~min}$ with insufflations of air every $10 \mathrm{~min}$. The acidic treatment generated anthocyanidins from homologous proanthocyanidins and flavonol aglycones from corresponding flavonol glycosides (Kaundun et al., 1998). The solution is left to cool for about $30 \mathrm{~min}$ (Solution A), and then except for $2 \mathrm{~mL}$ removed for measurement of the proanthocyanidins, the solution is filtered on a No. 3 porosity fritter. The flavonols are extracted from the filtered solution and from the filter wash liquid with $60 \mathrm{~mL}$ (two times) and then with $40 \mathrm{~mL}$ (once) of diethyl ether. These different fractions are then remixed and evaporated. The residue is conserved in the freezer in darkness and then mixed with $10 \mathrm{~mL}$ of methanol (Solution B) before analysis of the simple and total flavonols.

A volume of $2 \mathrm{~mL}$ taken from the Solution A is adjusted to $5 \mathrm{~mL}$ with $2 \mathrm{M} \mathrm{HCl}$. The total (pro)anthocyanidins are measured using an absorption spectrophotometer (Philips PU8620) at a wavelength of $530 \mathrm{~nm}$. As shown by Kaudun et al. (1998), the constant ratio between the different (pro)anthocynidins in Pinus halepensis needles allows a quantification of the mixture. The results are indicated as measurements of optical density (OD), since there are no standards.

A volume of $100 \mu \mathrm{L}$ of Solution B is left to react for $20 \mathrm{~min}$ in $5 \mathrm{~mL}$ of a $1 \% \mathrm{AlCl}_{3}$ methanol (w/w) solution. The total flavonols are measured by absorption spectrophotometry at a wavelength of $435 \mathrm{~nm}$ (measurement of the formation of colored complex intervening in presence of $\mathrm{Al}^{3+}$ ions). The quantitative results are expressed with reference to a standard set made with quercetin. 
Separation and quantification of the simple flavonols are performed using the Solution B by high performance liquid chromatography (Hewlett Packard series 1050, location?) equipped with a photodiode array detector. The column used is a ???Nucléosil $100 \mathrm{C} 18$ column (4.6 by 250 $\mathrm{mm}$ ) fitted with a stationary same-phase precolumn. The mobile phase consists of a ternary mixture of solvents: A, water with $10 \%$ (v/v) acetic acid; B, methanol; and C, tetrahydrofuran. Elution is performed at a flow rate of $1 \mathrm{~mL} \mathrm{~min}^{-1}$ on the following gradient: from 63:10:17 (A/B/C) to 23:60:17 in $40 \mathrm{~min}$. The simple flavonols are detected at $370 \mathrm{~nm}$. The injection loop is $10 \mu \mathrm{L}$. Identification of compounds is based on the comparison of their retention times and of their UV spectrum (from $250-600 \mathrm{~nm}$ ) with those of commercial standards (RothSochiel,?location), using the photodiode array detector. Calibration is external.

\section{Statistical Analysis}

Statistical analysis was performed using the software Statview and Statitcf(? manufacturer and location for the two softwares?). Concentrations of air pollutants between the different sites were compared by means of a one-way Anova. This was based on daily means for each of the pollutants (roughly 40 measurements per site and per pollutant). Variations in total phenol concentrations, total concentrations in proanthocyanidins and in flavonols, according to site, were determined by non-parametric Kruskal-Wallis tests, followed by a NKS test (six measurements per site for each of the chemical parameters).

A correlation matrix was devised on the basis of the full set of data on the concentrations (per individual) of total phenols, total proanthocyanidins, and total flavonols and the concentrations of each of the pollutants at the different sites, to assess whether there were significant statistical relations between these groups of data. A correlation matrix was also devised on the basis of concentrations per individual of simple flavonols and concentrations of each of the pollutants.

A principal components analysis (PCA) was performed. This concerned the concentrations of total phenols, total proanthocyanidins and total flavonols, and the air pollutant concentrations, on the basis of the full set of data for the samples, or 30 individual points (six individuals, five stations), and eight variables. On the basis of the coordinates of the individual points in the PCA, a hierarchical ascending classification of momentum of the order two was performed to allow statistical grouping of individuals.

\section{RESULTS}

The six study sites had statistically different air pollutant concentrations (one-way Anova, $p$ $<0.05$; Table 1). Cadarache (1) was characterized by low concent rations of all the measured pollutants. Gardanne (2) showed a high $\mathrm{SO}_{2}$ content. High $\mathrm{SO}_{2}$ and $\mathrm{O}_{3}$ concentrations were recorded at Sausset-les-Pins (4). Ste Marguerite (3) and Martigues (5) had high N-based compounds and $\mathrm{O}_{3}$ concentrations.

\section{Total Phenolic Compounds}

The concentrations of total phenols in current needles differ significantly between the various study sites (Kruskal-Wallis Test, $p<0.0001$; Fig. 2). Results show two groups: the first composed by Cadarache (1), Gardanne (2), and Sausset- les-Pins (4); the second by Martigues (5) and St Marguerite (3). The first group present significant higher concentrations than the second 
(NKS test, $p<0.05)$. There are significant negative correlations between the total phenol concentrations and concentrations of $\mathrm{NO}(r=-0.524, p<0.01), \mathrm{NO}_{2}(r=-0.766, p<0.01)$, other $\mathrm{NO}_{\mathrm{x}}(r=-0.682, p<0.01)$ and ozone $(r=-0.369, p<0.05)$.

Mean total proanthocyanidin concentrations are significantly different between the various study sites (Kruskal-Wallis Test, $p=0.0005$; Fig. 3). The highest concentrations are observed for specimens from Gardanne (2) and the lowest for specimens from Sausset-les-Pins (4). There are negative significant correlations between this parameter and the concentrations of $\mathrm{O}_{3}(r=$ $-0.625 ; p<0.01)$ and $\mathrm{SO}_{2}(r=-0.387 ; p<0.05)$.

Total flavonol concentrations differ significantly between the study stations (Kruskal-Wallis Test, $p=0.001$; Fig. 4). Martigues (5) shows the highest values, whereas Gardanne (2) has low concentrations. The total flavo nol concentration is correlated positively with the ozone concentration $(r=0.519, p<0.01)$ and negatively with the $\mathrm{SO}_{2}$ concentration $(r=-0.336, p<$ $0.05)$.

Figure 5 represents two-dimensional mapping of the PCA. Axis 1, representing $46.5 \%$ of the information, is characterized on the positive side by the $\mathrm{N}$ compound concentrations $\left(\mathrm{NO}_{\mathrm{x}}, \mathrm{NO}_{2}\right.$, and NO in decreasing order of importance) and on the negative side by total phenol concentrations. Axis 2, representing $25.3 \%$ of the information, is characterized on the positive side by ozone concentrations and on the negative side by proanthocyanidin concentrations. The distribution of individuals-points in Plan 1-2 shows homogeneity between individuals from the same study site. The hierarchical ascending classification distinguishes statistically two main groups of sites:

- The first includes the specimens from the sites of Sausset-les-Pins (4), Cadarache (1), and Gardanne (2) that are situated on the negative side of Axis 1. They are characterized by very high total phenol concentrations. These sites show fairly low $\mathrm{N}$ air pollutant concentrations. This group is subdivided secondarily into two subgroups, according to Axis 2. The Sausset-les-Pins site (4) shows high ozone concentrations, and is therefore situated on the positive values side of this axis, whereas the specimens from Cadarache (1) and Gardanne (2), situated on the negative side, show high values for proanthocyanidins.

- The second group includes specimens from the sites at Martigues (5) and Ste Marguerite (3). They are situated on the positive side of Axis 1 . These sites show very high concentrations of $\mathrm{N}$ based air pollutants. This group is subdivided into two subgroups. The Martigues site (5), with the higher ozone concentrations and lower proanthocyanidin concentrations, is thus placed on the positive values side of Axis 2 .

\section{Simple Flavonols}

Six simple flavonols: kaempferol, isorhamnetin, quercetin, larycitrin, myricetin, and syringetin have been identified in the needles of Pinus halepensis. They are arranged in order of elution (Table II). All these compounds contain two aromatic rings (A and B) and a heterocycle of three $\mathrm{C}$ atoms including a hydroxyl group on the Carbon 3. They differ from each other in the substitution number (methoxyl or hydroxyl groups) on Cycle B. For the whole set of study sites, kaempferol is the major compound $\left(0.475 \mathrm{mg} \mathrm{g}^{-1}\right.$ of dry matter \pm 0.06 ; Fig. 6$)$. For the five other compounds measured, the mean concentrations range from 0.050 to $0.238 \mathrm{mg} \mathrm{g}^{-1}$ dry matter. 
After kaempferol, the second major compound is isorhamnetin, followed by quercetin, larycitrin, myricetin, and syringetin, except at Cadarache where quercetin concentrations are higher than those of isorhamnetin (Table 2).

Correlation matrix shows several significant correlations

(i) negative between the $\mathrm{SO}_{2}$ and myricetin $(r=-0.423, p<0.01)$, quercetin $(r=-0.627, p<$ $0.01)$, isorhamnetin $(r=-0.0544, p<0.01)$, kaempferol $(r=-0.371, p<0.05)$, larycitrin $(r=-0.411, p<0.05)$, and syringetin $(r=-0.387, p<0.05)$,

(ii) positive between the $\mathrm{NO}_{2}$, the other nitrogen oxides and the syringetin (respectively $r=$ $0.520, p<0.01$ et $r=0.410, p<0.05)$, and

(iii) positive between the ozone and the myricetin $(r=0.385, p<0.05)$, larycitrin and the syringetin ( $r=0.445$ and 0.535 respectively, $p<0.01$ ). Only the NO concentration shows no significant relation with concentrations of the various flavonols $(0.003<r<0.275, p$ $>0.05)$.

\section{DISCUSSION}

The amounts of total phenols in the Pinus halepensis needles obtained in this study are of the same order as those found in other species of the same genus that are also exposed to air pollution, such as Pinus nigra Arn. (Giertych et al., 1999), Pinus sylvestris L. (Karolewski, 1990), or Pinus eldarica L. (Peñuelas et al., 1996). The six flavonols identified in the needles of Pinus halepensis have already been reported by other authors, which study these compounds in a chimiotaxonomic perspective (Kaundun, 1995; Kaundun et al., 1998). They found also kaempferol as the major compound. In their studies, quercetin and isorhamnetin are the second and third major compounds respectively and whereas we found the opposite. These flavonols are also present in other Pinus such as Pinus brutia L. and Pinus eldarica (Kaundun, 1995).

Atmospheric pollution level may be considered as a constant during the whole year with a slight increase during the summer and winter dry seasons (AIRFOBEP, 2000). The monitoring of air pollutants during the study period is thus confirmed by long-term records of air pollution at these sites. A direct concentration-effect relationship between air pollutant concentrations and phenol or flavonoid contents may be assumed. However, other environmental factors can cause variations of phenol and flavonoid contents. That is the reason why the sites have been chosen in a geographically limited area where trees were healthy (no symptom observed in a wide area including the sample site).

Negative correlations between $\mathrm{N}$ pollutants and total phenol may be explained by the positive action of these pollutants on the nitrate reductase activity (Krywult et al., 1996). An increase of nitrate reductase activity promotes the $\mathrm{N}$ assimilation and several studies have demonstrated the existence of negative correlations between concentrations of $\mathrm{N}$ and of phenolic compounds in the leaves of various Pinus (Giertych et al., 1999). When the concentration of atmospheric natural coumpounds $\left(\mathrm{CO}_{2}\right)$ is high, they may induce similar effects as anthropic pollutant. Indeed, Peñuelas et al. (1996) have observed a decrease in the total phenolic compounds in presence of strong air $\mathrm{CO}_{2}$ concentrations.

Similarly, with regard to the impact of ozone pollution on the total phenols, a negative correlation has been demonstrated. Few bibliographical studies have been undertaken on the 
impact of ozone on total phenols in plants kept under controlled environmental conditions (Howell, 1970; Louguet et al., 1989; Langebartels et al., 1990?spelling Langerbartels?; Jordan et al., 1991; Kainulainen et al., 1994; Booker et al., 1996). According to Howell (1970), high ozone concentrations could influence the enzymatic activity involved in the metabolism of the phenols. Langebartels et al. (1990)(?spelling Langerbartels) show an increase in the phenolic compounds in the presence of $\mathrm{O}_{3}$. However, Kainulainen et al. (1994) suggest that there is no response of the total phenols in the presence of strong $\mathrm{O}_{3}$ concentrations. Booker et al. (1996) showed an increase in total phenols with chronic exposure to ozone in previous year's needles of Pinus taeda. For this same species, no significant changes in total phenols were detected in the current year's needles by the same authors, Booker et al. (1996) and Jordan et al. (1991). Ozone impact on total phenol concentrations has given rise to many contradictory results and may be dependent on the species. For Pinus halepensis, Anttonen et al. (1995) and Pelloux et al. (2001) clearly showed that ozone induced a decrease in chlorophyll content and an increase in necrosis, as well as alterations in the $\mathrm{C}$ me tabolism.

This study did not reveal any correlation between concentrations of $\mathrm{SO}_{2}$ and of total phenols. However, significantly positive correlations between these two parameters are found in controlled environment, for Pinus sylvestris (Karolewski, 1990; Giertych and Karolewski, 1993) and even for a distant species such as Vicia faba L. (Nandi et al., 1990). High $\mathrm{SO}_{2}$ concentrations induce an increase in necrosis and a decrease in respiration, as well as other disorders of the vital functions (Pierre and Queiroz, 1981; Nandi et al., 1990). These alterations thus favor and facilitate the biosynthesis of phenols, since these compounds play a role in respiration (Rubin and Arcichowska, 1971 in Giertych et al., 1999). Similarly, the impact of sulfuric acid, in controlled environment, on Pinus nigra and on Pinus resinosa Ait. engenders an increase in the phenolic compounds (Zobel and Nighswander, 1991). The defense mechanisms would thus appear to be the same as in the presence of $\mathrm{SO}_{2}$. The results that we have obtained are thus different and show that it is difficult to offer evidence of the impact of $\mathrm{SO}_{2}$ on phenolic compounds in natural environment. Other environmental parameters may interact more strongly.

The impact of air pollutants on the total flavonoids, $\mathrm{O}_{3}$, and $\mathrm{SO}_{2}$ concentrations are negatively correlated with the total proanthocyanidins and positively correlated with the total flavonols. These results on the impact of $\mathrm{O}_{3}$ might be set alongside those of Vogt et al. (1991) and Chaves et al. (1993), who have shown that the flavonoids increase with strong UV levels. The contrasting behavior of these two chemical families might be explained by their competition in the metabolic pathways of biosynthesis (Cooper-Driver and Bhattacharya, 1998). The defense mechanisms of Pinus halepensis against these air pollutants may favor the increase in total flavonol, perhaps at the expense of the flavonoids. Measurement of these two parameters thus produces the same information with regard to $\mathrm{O}_{3}$ and $\mathrm{SO}_{2}$ pollution. Loponen et al. (2001) have studied impact of heavy metal pollution on several phenolic compounds in Betula pubescens leaves. They have shown inverse results: an increase of (+)-catechin content and a decrease in flavonol content with high level of pollution. The (+)-catechin monomers (flanan-3-ols) serve as a precursor in a chain of steps toward proanthocyanids, and dihydroflavonols can be the common precursors for flavonols and proanthocyanidins (Loponen et al., 2001). According to the air pollutant, certain enzymes may be activated and thus promote some metabolic pathways. This suggests that heavy metal and gaseous pollutant have antagonist impacts on the dihydroflavonol transformation into flavonols or proanthocyanidins. 
All the simple flavonols show significant correlations with one or several pollutants. It appears that syringetin reacts to numerous pollutants $\left(\mathrm{SO}_{2}, \mathrm{NO}_{2}, \mathrm{NO}_{\mathrm{x}}\right.$, and $\left.\mathrm{O}_{3}\right)$, but in opposite ways for different compounds. Thus, it cannot be called an easily interpretable bioindicator. Similarly, myricetin and larycitrin react positively to pollution by $\mathrm{O}_{3}$ and negatively to pollution by $\mathrm{SO}_{2}$. However, quercetin, isorhamnetin, and kaempferol contents present significant correlation only with $\mathrm{SO}_{2}$. They can be characterized in a highly significant manner pollution by $\mathrm{SO}_{2}$.

\section{CONCLUSIONS}

Changes in concentrations of total phenols, total flavonoids, and simple flavonols in needles of Pinus halepensis must be considered in relation to changes in concentrations of air pollutants under natural conditions. Total phenol concentrations characterize NO pollution, since they show highly significant negative correlations with this parameter. Total flavonoids (total proanthocyanidins and total flavonols) may be used as bioindicators of $\mathrm{O}_{3}$ pollution and to a lesser extent to $\mathrm{SO}_{2}$ pollution. Sulfur dioxide pollution is indicated by low concentrations of quercetin, isorhamnetin, and kaempferol in the plant. Other researches will be performed to characterize the level of a given pollutant, and to check these first field results.

\section{ACKNOWLEDGMENTS}

This study has been financed by the Région Provence-Alpes-Côtes d'Azur, by the AIRFOBEP, and by the AIRMARAIX (organizations responsible for air quality monitoring in this area). We thank M. Paul for kindly proofreading the manuscript.

\section{REFERENCES}

<bok>AIRFOBEP. 2000. Qualité de l'air de la région de l'étang de Berre et de l'Ouest des bouches-du-Rhône. Bilan de la période 1998/1999. (In French.) AIRFOBEP Publ. France. $</$ bok $>$

<jrn>Anttonen, S., J. Herranen, P. Peura, and L. Kärenlampi. 1995. Fatty acids and ultrastructure of ozone-exposed Aleppo pine (Pinus halepensis Mill.,) needles. Environ. Pollut. 87:235242. $</ \mathrm{jrn}>$

<jrn> Booker, F.L., S. Anttonen, and A.S. Heagle. 1996. Catechin, proanthocyanidin and lignin contents of loblolly pine (Pinus taeda) needles after chronic exposure to ozone. New Phytol. 132:483-492.</jrn>

$<$ jrn> Bortnick, S.M., and S.L. Stetzer. 2002. Sampling frequency guidance for ambient air toxics monitoring. J. Air Waste Manag. Assoc. July:867-876.??</jrn>

$<$ jrn>Chaves, N., J.C. Escudero, and C. Gutierrez-Merino. 1993. Seasonal variation of exudate of Cistus ladanifer. J. Chem. Ecol. 19:2577-2591.</jrn>

<unknown>Chappelka, A., G. Somers, J. Renfro, L.J. Sheppard, and J.N. Cape. 1999. Visible ozone injury on forest trees in Great Smoky Mountains National park, USA. Forest Growth Responses to the Pollution Climate of the 21st Century. Water Air Soil Pollut. 116:255 260.</unknown> 
$<$ jrn>Conti, M.E., and G. Cecchetti. 2001. Biological monitoring : Lichens as bioindicators of air pollution assessment - A review. Environ. Pollut. 114:471-492.</jrn>

$<$ jrn>Cooper-Driver, G., and M. Bhattacharya. 1998. Role of phenolics in plant evolution. Phytochemistry 49:1165-1174.</jrn>

<jrn>Giertych, M.J., and P. Karolewski. 1993. Changes in phenolic compounds content in needles of scots pine (Pinus sylvestris L.) seedlings following short term exposition to sulphur dioxide. Arboretum Kornickie 38:43-51.</jrn>

<jrn>Giertych, M.J., P. Karolewski, and L.O. De Temmerman. 1999. Foliage age and pollution alter content of phenolic compounds and chemical elements in Pinus nigra needles. Water Air Soil Pollut. 110:363-377.</jrn>

<jrn>Giordani, P., G. Brunialti, and D. Alleteo. 2002. Effects of atmospheric pollution on lichen biodiversity (LB) in a Mediterranean region (Liguria, northwest Italy). Environ. Pollut. 118:53-64. </jrn>

$<$ jrn $>$ Godefroid, S. 2001. Temporal analysis of the Brussels flora as indicator for changing environmental quality. Landscape Urban Planning 52:203-224.</jrn>

<bok>Haslam, E. 1989. Plant polyphenols. University Press Publ., Cambridge.</bok>

<jrn> Howell, R.K. 1970. Influence of air pollution on quantities of caffeic acid isolated from leaves of Phaseolus vulgaris. Phytopathology 60:1626-1629.</jrn>

<edb>Impens, R., and E. Delcarte. 1995. Réseaux de surveillance de la qualité de l'air à l'aide des plantes indicatrices en région Wallone. p. 21-28. In Rencontres et journées techniques: Bioindicateurs végétaux de la qualité de l'air, INRA/ADEME (Ed.), Paris, France, 14 Nov. 1995. ?publisher and location.</edb>

<jrn>Jordan, D.N., T.H. Green, A.H. Chappelka, B.G. Lockaby, R.S. Meldahl, and D.H. Gjerstad. 1991. Response of total tannins and phenolics in loblolly pine foliage exposed to ozone and acid rain. J. Chem. Ecol. 17:505-513.</jrn>

<jrn> Kainulainen, P., J.K. Holopainen, H. Hyttinen, and J. Oksanen. 1994. Effect of ozone on the biochemistry and aphid infestation of scots pine. Phytochemistry $35: 39-42 .</ j r n>$

<jrn>Karlsson, G.P., H. Pleijel, E. Sild, H. Danielsson, G. Sellden, L. Ericson, L. Skarby, P. Grennfelt, H. Rohde, and E. Thornelof. 1995. Clover Sweden: A national three-year study of the effects of tropospheric ozone on Trifolium subterraneum, L. Water Air Soil Pollut. $85: 1503-1508 .</ j \mathrm{rn}>$

$<$ jrn>Karolewski, P. 1990. Visible and invisible injury to scots pine (Pinus sylvestris L.) needles caused by sulphur dioxide. Arboretum Kornickie $35: 127-136 .</ j r n>$

$<$ jrn>Karolewski, P., and M.J. Giertych 1994. Influence of toxic metal ions on phenols in needles and roots and on root respiration of scots Pine seedlings. Acta Soc. Bot. Pol. 63:29 35. $</ \mathrm{jrn}>$

<jrn>Karolewski, P., and M.J. Giertych. 1995. Changes in the level of phenols during needle development in scots-pine populations in a control and polluted environment. Eur. J. For. Pathol. $25: 297-306 .</ j r n>$ 
<unknown>Kaundun, S.S. 1995. Contribution biochimique à la connaissance systématique et génétique du pin d'Alep (Pinus halepensis Mill.) et du douglas (Pseudotsuga menziesii Mirb.). (In France.) Thèse Université Lyon, France.</unknown>

$<$ jrn>Kaundun, S.S., P. Lebreton, and B. Fady. 1998. Geographical variability of Pinus halepensis Mill. as revealed by foliar flavonoids. Biochem. Syst. Ecol. 26:83-96.</jrn>

<jrn>Krywult, M., A. Karolak, and A. Bytnerowicz 1996. Nitrate reductase activity as an indicator of ponderosa pine response to atmospheric nitrogen deposition in the San Bernardino mountains. Environ. Pollut. 93:141-146.</jrn>

<edb>Langerbartels, C., W. Heller, K. Kerner, S. Leonardi, D. Rosemann, M. Schraudner, M. Trest, and H.J. Sandermann. 1990. Ozone-induced defense reaction in plants. Environmental Research with plants in closed chambers. p. 358-368. In Air pollution Research Reports of the EC26. EEC, Brussels</edb>

<jrn>Loponen, J., K. Lempa, V. Ossipov, M.V. Kozloov, A. Girs, K. Hangasmaa, E. Haukioja, and K. Pihlaja. 2001. Patterns in content of phenolic compounds in leaves of mountain birches along a strong pollution gradient. Chemosphere $45: 291-301$.</jrn>

<conf> Louguet, P., P. Malka, and D. Contour-Ansel. 1989. Etude comparée de la résistance stomatique et de la teneur en composés phénoliques foliaires chez trois clones d'Epicéas soumis à une pollution contrôlée par l'ozone et le dioxyde de soufre en chambre à ciel ouvert. p. 73-78. In T.J. Brasser and W.C. Mulder, W.C (ed.), Proceedings of the 8th World Clean Air Congress. Vol. 2: Man and his ecosystem, 11-15 Sept. 1989, Elsevier, The Hague. $</$ conf $>$

<jrn>Marigo, G. 1973. Sur une méthode de fractionnement et d'estimation des composés phénoliques chez les végétaux. Analytica $2: 106-110 .</ j \mathrm{jn}>$

<jrn>Manning, W.J., B. Godzik, and R. Musselman 2002. Potential bioindicator plant species for ambient ozone in forested mountain areas of central Europe. Environ. Pollut. 119:283 $290 .</ j \mathrm{rn}>$

<jrn>Muzika, R.M. 1993. Terpenes and phenolics in response to nitrogen fertilization: A test of carbon/nutrient balance hypothesis. Chemoecology 4:3-7.</jrn>

<jrn>Nandi, P.K., M. Madhoolika Agrawal, S.B. Agrawal, and D.N. Rao. 1990. Physiological responses of Vicia faba to sulfur dioxide. Ecotoxicol. Environ. Saf. 19:64-71.</jrn>

<unknown>Oleksyn, J., P.B. Reich, P. Karolewski, M.G. Tjoelker, and W. Chalupka. 1999. Nutritional status of pollen and needles of diverse Pinus sylvestris populations grown at sites with contrasting pollution. Water Air Soil Pollut. 110:195-212.</unknown>

$<$ jrn>Pelloux, J., Y. Jolivet, V. Fontaine, J. Banvoy, and P. Dizengremel. 2001. Changes in RuBisCo en rubisco activase gene expression and polypeptide content in Pinus halepensis M. subjected to ozone and drought. Plant Cell Environ. 24:123-131.</jrn>

<jrn>Peñuelas, J., M. Estiarte, B.A. Kimball, S.B. Idso, P.J. Pinter, G.W. Wall, R.L. Garcia, D.J. Hansaker, R.L. LaMorte, and D.L. Hendrix. 1996. Variety of responses of plant phenolic concentration to $\mathrm{CO}_{2}$ enrichment. J. Exp. Bot. 47:1463-1467.</jrn> 
$<$ jrn> Pierre, M., and O. Queiroz. 1981. Enzymic and metabolic changes in bean leaves during continuous pollution by subnecrotic levels of $\mathrm{SO}_{2}$. Environ. Pollut. $25: 41-51$. </jrn>

<jrn>Pisani, J.M., and R.A. Distel. 1998. Inter and intraspecific variations in production of spines and phenols in Prosopis caldemia and Prosopis flexuosa. J. Chem. Ecol. 24:23 36. $</ \mathrm{jrn}>$

<jrn> Rahman, U., M.A. Awan, S.T. Hassan, and M.M. Khattak. 2000. Mosses as indicators of atmospheric pollution of trace metals $(\mathrm{Cd}, \mathrm{Cu}, \mathrm{Ph}, \mathrm{Mn}$ and $\mathrm{Zn})$ in the vicinity of cold-fired brick kilns in north-eastern suburbs of Islamabad. Pakistan. J. Radioanal. Nuclear Chem. 246:331-336. </jrn>

<jrn> Rautio, P., S. Huttunen, E. Kukkola, R. Peura, and J. Lamppu. 1998. Deposited particles, element concentrations and needles injuries on Scots pines along an industrial pollution transect in northern Europe. Environ. Pollut. 103:81-89.</jrn>

$<$ jrn> Rhodes, M.J.C. 1994. Physical role for secondary metabolites in plants: Some progress, many outstanding problems. Plant Mol. Biol. 24:1-20.</jrn>

<jrn> Rodrigues, G.S., S.A. Madkour, and L.H. Weinstein. 1996. Genotoxic activity of ozone in Tradescantia. Environ. Exp. Bot. 36:45-50.</jrn>

<jrn> Rossbach, M., R. Jayasekera, G. Kniewald, and N.H. Thang. 1999. Large scale air monitoring: Lichen vs. air particulate matter analysis. Sci. Total Environ. 232:59-66. </jrn>

<jrn>Vassileva, E., V. Velev, C. Daiev, T. Stoichev, M. Martin, D. Robin, and W. Haerdi. 2000. Assessment of heavy metals air pollution in urban and industrial environments using oak leaves as bioindicators. Intern. J. Environ. Analyt. Chem. 78:159-173.</jrn>

<jrn>Vogt, T., P.G. Gülz, and H. Reznik. 1991. UV radiation dependent flavonoid accumulation of Cistus laurifolius L. Zeitschrift für Naturforschung 46c:37-42.</jrn>

$<$ bok>Waterman, P.G., and S. Mole. 1994. Analysis of phenolic plant metabolites. Blackwell Scientific Publ., London. </bok>

$<$ jrn $>$ Zobel, A., and J.E. Nighswander. 1991. Accumulation of phenolic compounds in the necrotic areas of Austian and red pine needles after spraying with sulphuric acid: A possible bioindicator of air pollution. New Phytol. 117:565-574.</jrn>

Fig. 1. Localization of study sites.

Fig. 2. Mean concentrations of total phenolic compounds in needles of Pinus halepensis (mg gallic acid $\mathrm{g}^{-1}$ dry matter \pm standard deviation) for the various study sites.

Fig. 3. Concentrations of total proanthocyanidins in needles of Pinus halepensis (OD \pm standard deviation) for the various study sites.

Fig. 4. Mean concentrations of total flavonols in needles of Pinus halepensis (mg of Quercetin $\mathrm{g}^{-1}$ dry matter \pm standard deviation) for the various study sites.

Fig. 5. Two-dimensional mapping of the Principal Component Analysis performed for total phenols, total proanthocyanidins, total flavonols, and air pollutants. 
Fig. 6. Mean concentrations of simple flavonols (in $\mathrm{mg} \mathrm{g}^{-1}$ dry matter \pm standard deviation) for the whole set of study sites.

Table 1. Mean concentrations of air pollutants at the study sites (in $\mu \mathrm{g} \mathrm{m}^{-3}$ ).

\begin{tabular}{cccccc}
\hline Stations & $\mathbf{N O}$ & $\mathbf{N O}$ & $\mathbf{N O}_{\mathbf{2}}$ & $\mathbf{O}_{\mathbf{3}}$ & $\mathbf{S O}_{\mathbf{2}}$ \\
\hline 1. Cadarache & 4.49 & 13.82 & 14.27 & 37.90 & 2.30 \\
2. Gardanne & 3.11 & 13.55 & 15.70 & 31.70 & 14.53 \\
3. Ste Marguerite & 13.09 & 30.96 & 27.15 & 40.24 & 6.85 \\
4. Sausset-les-Pins & 2.14 & 11.70 & 13.78 & 43.59 & 18.70 \\
5. Martigues & 5.81 & 23.05 & 26.92 & 42.76 & 7.38 \\
\hline
\end{tabular}

Table 2. Mean concentrations (in $\mu \mathrm{g} \mathrm{g}^{-1}$ dry matter \pm standard deviation) of simple flavonols for the various study sites $(n=6)$.

\begin{tabular}{llllll}
\hline & $\begin{array}{c}\text { Cadarache } \\
(\mathbf{1})\end{array}$ & \multicolumn{1}{c}{ Gardanne (2) } & $\begin{array}{c}\text { Ste Marguerite } \\
(\mathbf{3})\end{array}$ & $\begin{array}{c}\text { Sausset-les- } \\
\text { Pins (4) }\end{array}$ & Martigues (5) \\
\hline Myricetin & $92.5 \pm 25.0$ & $40.8 \pm 26.6$ & $62.6 \pm 17.0$ & $73.2 \pm 13.5$ & $82.3 \pm 23.4$ \\
Larycitrin & $143.0 \pm 41.3$ & $81.2 \pm 38.5$ & $121.0 \pm 25.8$ & $121.1 \pm 11.6$ & $161.3 \pm 42.5$ \\
Quercetin & $323.3 \pm 75.4$ & $169.3 \pm 39.5$ & $194.0 \pm 91.3$ & $160.2 \pm 61.1$ & $276.3 \pm 66.9$ \\
Syringetin & $54.6 \pm 22.8$ & $33.1 \pm 7.4$ & $57.7 \pm 14.0$ & $49.9 \pm 6.1$ & $76.8 \pm 13.3$ \\
Isorhamnetin & $321.0 \pm 88.8$ & $212.8 \pm 63.1$ & $234.4 \pm 63.7$ & $194.4 \pm 68.9$ & $344.0 \pm 88.8$ \\
Kaempferol & $542.6 \pm 79.3$ & $437.6 \pm 102.4$ & $499.0 \pm 65.8$ & $493.5 \pm 68.4$ & $509.2 \pm 72.6$ \\
\hline
\end{tabular}

